\title{
Arabidopsis thaliana exudates induce growth and proteomic changes in Gluconacetobacter diazotrophicus
}

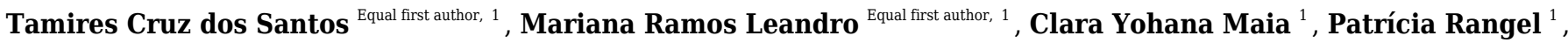 \\ Fabiano S Soares ${ }^{1}$, Ricardo Reis ${ }^{1}$, Lucas Passamani ${ }^{1}$, Vanildo Silveira ${ }^{1}$, Gonçalo Apolinário de Souza Filho ${ }^{\text {Corresp. } 1}$ \\ ${ }^{1}$ Laboratório de Biotecnologia/Unidade de Biologia Integrativa, Universidade Estadual do Norte Fluminense, Campos dos Goytacazes, Rio de Janeiro, \\ Brazil \\ Corresponding Author: Gonçalo Apolinário de Souza Filho \\ Email address: goncalos@uenf.br
}

Background. Plants interact with a variety of microorganisms during their life cycle, among which beneficial bacteria deserve special attention. Gluconacetobacter diazotrophicus is a beneficial bacterium able to fix nitrogen and promote plant growth. Despite its biotechnological potential, the mechanisms regulating the interaction between $\mathrm{G}$. diazotrophicus and host plants remain unclear.

Methods. We analyzed the response of G. diazotrophicus to cocultivation with Arabidopsis thaliana seedlings. Bacterial growth in response to cocultivation and plant exudates was analyzed. Through comparative proteomic analysis, $G$. diazotrophicus proteins regulated during cocultivation were investigated. Finally, the role of some up-accumulated proteins in the r esponse $\mathrm{G}$. diazotrophicus to cocultiv ation was analyzed by reverse genetics, using insertion mutants.

Results. Our results revealed the induction of bacterial growth in response to cocultivation. Comparative proteomic analysis identified 450 bacterial proteins, with 39 up-accumulated, and 12 down-accumulated in response to cocultivation. Among the up-accumulated pathways, the metabolism of pentoses and protein synthesis were highlighted. Proteins potentially relevant to bacterial growth response such as ABC-F-Etta, ClpX, Zwf, MetE, AcnA, IlvC, and AccC were also increased. Reverse genetics analysis, using insertion mutants, revealed that the lack of ABC-F-Etta and AccC proteins severely affects G.

diazotrophicus response to cocultivation. Our data demonstrated that specific mechanisms are activated in the bacterial response to plant exudates, indicating the essential role of "ribosomal activity" and "fatty acid biosynthesis" in such a process. This is the first study to demonstrate the participation of EttA and AccC proteins in plant-bacteria interactions, and open new perspectives for understanding the initial steps of such associations. 
1 Arabidopsis thaliana exudates induce growth and proteomic changes in Gluconacetobacter

\section{2 diazotrophicus}

3 Tamires Cruz dos Santos ${ }^{1 *}$, Mariana Ramos Leandro ${ }^{1 *}$, Clara Yohana Maia ${ }^{1}$, Patricia Louzada

4 Rangel $^{1}$, Fabiano Silva Soares ${ }^{1}$, Ricardo Souza Reis ${ }^{1}$, Lucas Zanchetta Passamani ${ }^{1}$, Vanildo

5 Silveira $^{1}$, Gonçalo Apolinário de Souza Filho ${ }^{1}$

6

7 1Laboratório de Biotecnologia/Unidade de Biologia Integrativa, Universidade Estadual do Norte

8 Fluminense, Campos dos Goytacazes, Rio de Janeiro, Brazil

9

$10 *$ These authors contributed equally.

11

12 Corresponding author:

13 Gonçalo Apolinário de Souza Filho

14 Av. Alberto Lamego, Campos dos Goytacazes, RJ, 28013-602, Brazil

15 Email address: goncalos@uenf.br

16 


\section{Abstract}

18 Background. Plants interact with a variety of microorganisms during their life cycle, among which beneficial bacteria deserve special attention. Gluconacetobacter diazotrophicus is a beneficial bacterium able to fix nitrogen and promote plant growth. Despite its biotechnological potential, the mechanisms regulating the interaction between $G$. diazotrophicus and host plants remain unclear.

23 Methods. We analyzed the response of G. diazotrophicus to cocultivation with Arabidopsis 24 thaliana seedlings. Bacterial growth in response to cocultivation and plant exudates was 25 analyzed. Through comparative proteomic analysis, G. diazotrophicus proteins regulated during cocultivation were investigated. Finally, the role of some up-accumulated proteins in the response $G$. diazotrophicus to cocultivation was analyzed by reverse genetics, using insertion 28 mutants.

Results. Our results revealed the induction of bacterial growth in response to cocultivation.

30 Comparative proteomic analysis identified 450 bacterial proteins, with 39 up-accumulated, and 12 down-accumulated in response to cocultivation. Among the up-accumulated pathways, the metabolism of pentoses and protein synthesis were highlighted. Proteins potentially relevant to bacterial growth response such as ABC-F-Etta, ClpX, Zwf, MetE, AcnA, IlvC, and AccC were

34 also increased. Reverse genetics analysis, using insertion mutants, revealed that the lack of ABCF-Etta and AccC proteins severely affects G. diazotrophicus response to cocultivation. Our data demonstrated that specific mechanisms are activated in the bacterial response to plant exudates, indicating the essential role of "ribosomal activity" and "fatty acid biosynthesis" in such a process. This is the first study to demonstrate the participation of EttA and AccC proteins in plant-bacteria interactions, and open new perspectives for understanding the initial steps of such associations. 


\section{Introduction}

The interaction between bacteria and plants involves complex recognition and signaling mechanisms that activate specific responses $[1,2]$. Among plant-associated microorganisms, the importance of plant growth-promoting bacteria (PGPB) in agriculture has been increasing, reducing the demand for industrialized fertilizers [3,4]. PGPB may interact with plants by colonizing the rhizosphere or the surfaces of leaves and roots or by establishing endophytic colonization $[5,6]$.

Gluconacetobacter diazotrophicus is an endophytic nitrogen-fixing PGPB that was isolated for the first time from sugarcane plants [7]. This bacterium can colonize other plant species such as sweet potato, pineapple, coffee, and Arabidopsis [8,9]. Among the relevant characteristics of this bacterium is its ability to colonize and promote the growth of both dicot and monocot plants [7,9]. G. diazotrophicus is considered a bacterial model for the study of endophytic associations, providing a better understanding of the pathways involved in this process [10-12].

Souza et al., 2016, showed that G. diazotrophicus establishes a positive endophytic association with Arabidopsis thaliana resulting in biomass gain and increased photosynthetic efficiency. In addition, the early stages of the association of G. diazotrophicus with A. thaliana appears to activate specific responses of the plant immune system, but even so G. diazotrophicus is able to colonize and promote plant growth [13]. Although some studies have sought to elucidate the molecular mechanisms modulating the interaction between $G$. diazotrophicus and sugarcane, few studies have addressed such mechanisms in dicot host plants $[11,14,15]$. 
$65[11,12,14,15]$. Proteomic approaches have been used to analyze the main pathways regulated in

66 G. diazotrophicus when exposed to exudates from sugarcane, revealing regulation of specific

67 responses, as the induction of proteins related to carbohydrate and energy metabolism, and

68 transcription and translation processes $[11,14]$. However, the molecular mechanisms modulating

69 such interactions are still unclear, particularly those activated during the association with dicot

70 host plants.

71 The present work aims to evaluate the physiological and molecular responses of $G$.

72 diazotrophicus to cocultivation with $A$. thaliana seedlings. Bacterial growth in response to

73 cocultivation and plant exudates was analyzed. Through comparative proteomic analysis, $G$.

74 diazotrophicus proteins regulated during cocultivation were investigated. The role of some up-

75 accumulated proteins in the response $G$. diazotrophicus to cocultivation was analyzed by reverse

76 genetics, using insertion mutants. The results allowed us to identify mechanisms essential for

77 bacterial response to cocultivation with Arabidopsis seedlings.

\section{Materials \& Methods}

80

81

82

83

84

85

86

\subsection{Plants and Growth Conditions}

Seeds of $A$. thaliana (Col-0) were germinated in vitro in Petri dishes containing half-strength MS medium liquid [16] with $0.5 \%$ sucrose and $0.05 \%$ MES buffer. The seedlings were cultivated for ten days at $23^{\circ} \mathrm{C}$ under $60 \%$ relative humidity and $70 \mu \mathrm{mol} \mathrm{m} \mathrm{m}^{-2}$ light $(12 \mathrm{~h}$ photoperiod). Roots were not covered from the light during the $12 \mathrm{~h}$ photoperiod. 

from the culture collection of the Universidade Estadual do Norte Fluminense Darcy Ribeiro

89 (UENF, Campos dos Goytacazes, Rio de Janeiro State, Brazil). The insertional mutants of $G$.

90 diazotrophicus PA15, defective in production of the proteins EttA (A9H4G2), AccC (A9HEX0), 91 and Zwf (A9H326) were obtained from the "G. diazotrophicus PA15 mutant library" of the

92 Laboratório de Biotecnologia - UENF [17]. Such a mutant library was obtained by using EZ-

93 Tn5 < R6Kyori/KAN-2>Tnp insertion kit (Epicentre, Madison, WI, USA).

G. diazotrophicus wild-type and mutant strains were grown in DYGS medium composed

95 of $\left(\mathrm{g} . \mathrm{L}^{-1}\right) 2.0$ glucose; 1.5 bacteriological peptone; 2.0 yeast extract; $0.5 \mathrm{~K}_{2} \mathrm{HPO}_{4}, 0.5 \mathrm{MgSO}_{4}$

$96.7 \mathrm{H}_{2} \mathrm{O}$; and 3.75 glutamic acid; with the $\mathrm{pH}$ of the medium adjusted to 6.0 [8]. Bacterial cells

97 were cultivated under constant agitation and temperature $\left(250 \mathrm{~min}^{-1}\right.$ and $\left.30^{\circ} \mathrm{C}\right)$ in a shaker $(\mathrm{C} 25$

98 Incubator, New Brunswick Scientific, Edison, NJ, USA) until reaching an optical density

99 (O.D.600) equal to $1.0\left(\sim 10^{8}\right.$ cells. $\left.\mathrm{mL}^{-1}\right)$.

\subsection{Plant-Bacteria cocultivation}

102 Ten A. thaliana seedlings were grown in vitro for ten days in Petri dishes containing 18

$103 \mathrm{~mL}$ of half-strength MS medium plus $0.5 \%$ sucrose without the addition of hormones. After

104 reach O.D.600 1.0, G. diazotrophicus wild-type and mutant strains cells were washed three times

105 three times with $0.85 \%(\mathrm{v} / \mathrm{v}) \mathrm{NaCl}$ to prevent carryover of spent growth medium. Then, ten ten-

106 day-old $A$. thaliana seedlings were inoculated with $G$. diazotrophicus wild-type and mutant

107 strains at a final concentration of $10^{7}$ cells $\mathrm{mL}^{-1}$, as described in the previous item (9 repetitions

108 of each treatment, including control). Control treatment was performed by inoculation of $G$.

109 diazotrophicus wild-type and mutant strains at a concentration of $10^{7}$ cells $\mathrm{mL}^{-1}$ in MS medium 
110 without $A$. thaliana seedlings. Petri dishes were maintained at $23^{\circ} \mathrm{C}$ under an irradiance of 120

$111 \mathrm{~mol} /$ photons $\mathrm{m}^{-2} \mathrm{~s}^{-1}$ for 24 hours. Bacterial growth was quantified by optical density (O.D.600)

112 analysis.

113

114 2.4 Proteomic Analysis

115 2.4.1 Protein extraction

116 Three biological replicates of G. diazotrophicus cells were collected from cultures in

117 MS medium (control) and from G. diazotrophicus/A. thaliana cocultivation, and were used for

118 proteomic analysis. For this purpose, $6.5 \mathrm{ml}$ of each cultivation medium sample was centrifuged

119 to collect the bacteria. Protein extraction of all samples was performed as previously described

120 by Passamani et al. (2017) [18]. Specifically, after discarding the supernatant, the pellets were

121 resuspended in $300 \mu \mathrm{L}$ of the TCA/acetone precipitation buffer $(10 \%$ trichloroacetic acid in

122 acetone with $20 \mathrm{mM}$ dithiothreitol-DTT) and maintained under constant stirring for $60 \mathrm{~min}$ at

$1234^{\circ} \mathrm{C}$. Samples were, then, maintained at $-20^{\circ} \mathrm{C}$ for $60 \mathrm{~min}$ and centrifuged $\left(30 \mathrm{~min} ; 4^{\circ} \mathrm{C} ; 12.000\right.$

124 g). The supernatants were discarded, and the pellets were rinsed three times with ice-cold

125 acetone containing $20 \mathrm{mM}$ DTT, followed by centrifugation $\left(5 \mathrm{~min} ; 4^{\circ} \mathrm{C} ; 12,000 \mathrm{~g}\right)$. The

126 supernatants were discarded, and the pellets were maintained at room temperature to dry. The

127 pellets were resuspended in $300 \mu \mathrm{L}$ of urea/thiourea extraction buffer $(7 \mathrm{M}$ urea, $2 \mathrm{M}$ thiourea,

$1281 \%$ DTT, 2\% Triton X-100, $5 \mu \mathrm{M}$ pepstatin, $1 \mathrm{mM}$ phenylmethanesulfonylfluoride-PMSF) and

129 maintained under stirring until complete homogenization. The samples were centrifuged (15 min;

$\left.1304^{\circ} \mathrm{C} ; 12.000 \mathrm{~g}\right)$, and the supernatants were collected.

131 The total protein concentration of the samples was estimated using the 2-D Quant Kit

132 (GE Healthcare, UK) following the manufacturer's recommendations. The absorbance of each 
133 sample and a standard curve with bovine albumin serum (BSA, GE Healthcare, UK) was

134 determined in a Synergy 2 Multimode Reader (Biotek Instruments, USA) at $485 \mathrm{~nm}$. Protein

135 samples were stored in an ultra-freezer at $-80^{\circ} \mathrm{C}$.

137 2.4.2 Protein digestion

138 Protein extracts $(100 \mu \mathrm{M})$ were precipitated in methanol/chloroform as described by

139 Nanjo et al. (2012). Then, protein extracts were digested as previously described by Passamani et

140 al (2017). Specifically, pellets were resuspended in $25 \mu \mathrm{L}$ of $0.2 \%$ (v/v) RapiGest surfactant

141 (Waters, Milford, CT). Samples were, then, vortexed rapidly and incubated in a heated mixer at

$14280^{\circ} \mathrm{C}$ for $15 \mathrm{~min}$, and $2.5 \mu \mathrm{l}$ of $100 \mathrm{mM}$ DTT (Bio-Rad Laboratories, Hercules, CA) was added.

143 Subsequently, the samples were vortexed and incubate for $30 \mathrm{~min}$ at $60^{\circ} \mathrm{C}$ under constant shaking

144 at $350 \mathrm{rpm}$. Then, $2.5 \mu \mathrm{L}$ of $300 \mathrm{mM}$ iodoacetamide (GE Healthcare, Piscataway, NJ) was added

145 in each sample. The samples were, then, vortexed rapidly and incubated for 30 min in the dark at

146 room temperature. Subsequently, digestion was performed by adding $20 \mu \mathrm{L}$ of $50 \mathrm{ng} / \mu \mathrm{L}$ trypsin

147 solution (Promega, WI, USA) prepared in $50 \mathrm{mM}$ ammonium bicarbonate buffer. The samples

148 were, then, incubated overnight at $37^{\circ} \mathrm{C}$. The precipitation of RapiGest was performed by adding

$14910 \mu \mathrm{l}$ of $5 \%(\mathrm{v} / \mathrm{v})$ trifluoroacetic acid, and the tubes were incubated for $30 \mathrm{~min}$ at $37^{\circ} \mathrm{C}$, followed

150 by centrifugation $\left(30 \mathrm{~min} ; 8^{\circ} \mathrm{C} ; 15.000 \mathrm{~g}\right.$ ). Subsequently, tryptic digestions were desalted using

151 Pierce C18 spin columns (Thermo Scientific) according to the manufacturer's instructions. The

152 eluted peptides were then vacuum dried and reconstituted in $50 \mathrm{mM}$ ammonium bicarbonate plus

$1530.1 \%$ formic acid and adjusted to a final concentration of $2 \mu \mathrm{g} \mu \mathrm{L}^{-1}$. The digested samples were

154 then transferred to total recovery flasks (Waters, CT, USA). 
156

157

158

159

160

161

162

163

164

165

166

167

168

169

170

171

172

173

174

175

176

177

178

\subsubsection{LC-MS/MS analyses}

LC-MS/MS analyses were performed as previously described by Passamani et al. (2017).

Specifically, a liquid nanoACQUITY ultraperformance UPLC connected to a Q-TOF SYNAPT

G2-Si HDMS (Waters) mass spectrometer was used for LC-MS-HDMSE analysis. The

chromatographic step was performed by injecting two $\mu \mathrm{L}$ of the digested samples for sample

normalization before the relative quantification of proteins. In the separation step, the samples

(digested protein, $2 \mu \mathrm{g})$ were loaded into the nanoACQUITY UPLC $5 \mu \mathrm{m}$ C18 $(180 \mu \mathrm{m} \times 20$

$\mathrm{mm}$ ) column at five $\mu \mathrm{min}^{-1}$ for $3 \mathrm{~min}$ and then into the nanoACQUITY HSS T3 $1.8 \mu \mathrm{m}$

analytical reversed-phase column $(75 \mu \mathrm{m} \times 150 \mathrm{~mm})$ at $400 \mathrm{~nL} \mathrm{m^{-1 }}$. The temperature of the

column was set to $45^{\circ} \mathrm{C}$. For the elution of the peptides; a binary gradient was used: mobile

phase A consisted of water (Tedia) and 0.1\% formic acid (Sigma-Aldrich), and mobile phase B

consisted of acetonitrile (Sigma-Aldrich) and $0.1 \%$ formic acid. Gradient elution was performed

as follows: $7 \%$ B over $3 \mathrm{~min}$, increased from 7 to $40 \% \mathrm{~B}$ at $90.09 \mathrm{~min}$; then 40 to $85 \% \mathrm{~B}$ at 94.09

min; held constant at $85 \%$ until $98.09 \mathrm{~min}$; decreased to $7 \% \mathrm{~B}$ at $100.09 \mathrm{~min}$, and finally held

steady at $7 \%$ B until the end of the run at $108.09 \mathrm{~min}$. The mass spectrometer was operated in

resolution mode (V mode) and positive mode with ionic mobility; with collision energy transfer

from 19 to $45 \mathrm{~V}$ in high-energy mode; a voltage and capillary cone of $30 \mathrm{~V}$ and $2800 \mathrm{~V}$,

respectively; and a source temperature of $70^{\circ} \mathrm{C}$. In the TOF parameters, the scan time was set to

$0.5 \mathrm{~s}$ in continuous mode, with a mass range of 50 to $2000 \mathrm{Da}$. Human [Glu1]-fibrinopeptide B

(Sigma-Aldrich) at $100 \mathrm{fmol} . \mu \mathrm{L}^{-1}$ was used as an external calibrant, with acquisition performed every 30 s. Mass spectrum acquisition was performed by using MassLynx v4.0 software.

\subsubsection{Proteomic data analysis}


180 Passamani et al. (2018) [20], through ProteinLynx Global Server (PLGS; version 3.0.2) (Waters)

181 and ISOQuant workflow software [21,22]. Specifically, the PLGS analysis was performed with

182 the follows processing parameters: a low energy threshold of 150 (counts), a high energy

183 threshold of 50, and an intensity threshold of 750. Additionally, the analysis was performed with

184 the following parameters adjustment were made: two missed cleavages, minimum fragment ions

185 per peptide equal to 3 , minimum ions per peptide equal to 7 , minimum peptides per protein equal

186 to 2, fixed carbamidomethyl (C) modifications and variable modifications of oxidation (M) and

187 phosphorylation (STY). The false discovery rate (FDR) for the identification of peptides and

188 proteins was established according to a maximum of $1 \%$, with a minimum peptide length of 6

189 amino acids. Proteomic data were processed using the Gluconacetobacter diazotrophicus

190 RIOGENE proteome database (www.uniprot.org/proteomes/UP000001176).

191 After data analysis in ISOQuant, only the proteins that were present or absent (for single

192 proteins) in all three biological replicates were considered in the differential abundance analysis.

193 Data were analyzed using Student's t-test (two-tailed) as previously described by Leandro et al.

1942019 [23]. Specifically, proteins with p values $<0.05$ were considered to be up-accumulated if

195 the fold change (FC) was higher than 1.5 and down-accumulated if the FC was less than 0.667.

196 Protein network analyses was performed using STRING database with confidence as the

197 meaning of network edges and 0.700 of interaction score (high confidence) (www.string-db.org). 198

1992.5 Sample preparation of the plant, bacterial and cocultivation exudates 
201 thaliana cocultivations were obtained, as illustrated in Figure S1. Three biological replicates of 202 each treatment were performed.

$204 \mathrm{MS}$ medium at $23^{\circ} \mathrm{C}$ for ten days. Plant exudates were collected by filtration of the cultivation 205 medium with syringe filters $(0.22 \mu \mathrm{m})$ and stored at $-80^{\circ} \mathrm{C}$.

In order to obtain $G$. diazotrophicus exudates, the bacteria were inoculated in Petri dishes containing $18 \mathrm{ml}$ of half-strength MS medium and cultivated for 24 hours at $23^{\circ} \mathrm{C}$. When the bacterial cultures reached an O.D.600nm $=1.0$, the culture was transferred to centrifuge tubes and centrifuged at $8000 \mathrm{~g}$ for $5 \mathrm{~min}$. The supernatant was filtered with a syringe filter $(0.22 \mu \mathrm{m})$ and 210 stored at $-80^{\circ} \mathrm{C}$.

211 Exudates from the cocultivation of $A$. thaliana seedlings and G. diazotrophicus were

212 obtained from cocultivation assays performed as previously described in item 2.3. After

213 cocultivation, the medium was collected and centrifuged at $8000 \mathrm{~g}$ for $5 \mathrm{~min}$. The supernatant 214 was filtered with a syringe filter $(0.22 \mu \mathrm{m})$ and stored at $-80^{\circ} \mathrm{C}$.

\subsection{Analysis of the G. diazotrophicus PA15 response to exudates}

217 Exudates from G. diazotrophicus, A. thaliana seedlings, or cocultivation, were previously

218 obtained as described in Section 2.5. Such exudates were added to G. diazotrophicus cultivation, 219 as shown in Figure S1. G. diazotrophicus culture (O.D. $\left.{ }_{600 \mathrm{~nm}}=1.0\right)$ produced as described in 220 Section 2.2 was inoculated in $50 \mathrm{~mL}$ Erlenmeyer flasks containing half-strength fresh MS 221 medium and each exudate, as the following final proportion: 10\% (G. diazotrophicus culture), $22245 \%$ (fresh MS medium) and 45\% (exudate). Control samples received 10\% of $G$. 
223 diazotrophicus and 90\% of half-strength fresh MS medium. All cultures had a final volume of 10

$224 \mathrm{ml}$. The cultures were grown at $30^{\circ} \mathrm{C}$, with constant agitation $(250 \mathrm{rpm})$ in an orbital shaker.

225 Bacterial growth was analyzed by optical spectrometry (O.D.600). Three biological replicates

226 were performed for each treatment.

227

228

\subsection{Phylogenetic analyses and genomic organization of acc C and ettA}

229

The sequences of AccC and EttA proteins coding genes of G. diazotrophicus (RefSeq:

230 NC_010125.1), and related bacterial species were obtained through the NCBI database. The

$231 a c c C$ and ettA locus of Gluconacetobacter xylinus NBRC 3288 (RefSeq: NC_016037),

232 Azospirillium brasilense Sp245 (RefSeq: NZ_CP022253.1), Herbaspirillum seropedicae SmR1

233 (RefSeq: NC_014323), Pseudomonas syringae pv. tomato str. DC3000 (RefSeq: NC_004578.1),

234 and Escherichia coli ATCC8739 (RefSeq: NZ_CP022959.1) were used for the analysis of

235 phylogeny, gene context and operon prediction.

236 Gene sequences were aligned with MEGA-X software version 10.1.7 [24] using the

237 ClustalW algorithm (default settings). MEGA-X was also used to select the best substitution

238 models for phylogenetic analyses, and to generate a phylogenetic tree using the maximum

239 likelihood (ML) method. The parameters selected for $a c c C$ and $e t t A$ phylogenetic threes were the

240 models of substitution Gama Time Reversible (GTR) with the invariant site (I) and GTR with the

241 gamma-distributed site, respectively, with 1000 bootstraps.

242 The KEGG [http://www. https://www.genome.jp/kegg/] and Microbes databases

243 [http://www.microbesonline.org/] were used for an in silico prediction of the operon

244 organization. 
246

247

248

249

250

251

252

253

254

255

256

257

258

259

260

261

262

263

264

265

266

267

\subsection{Statistical analyses}

The assays were performed with nine replicates in each condition. The growth rate data of $G$. diazotrophicus wild-type and mutant strains under the control and cocultivation treatments were subjected to a mean test (Tukey) at the 5\% probability level to measure significance between treatments. Data analyses were performed by using GraphPad Prism v. 7.00.159 (GraphPad Software, La Jolla, CA, USA).

\section{Results}

3.1 G. diazotrophicus growth increases in response to cocultivation with A. thaliana G. diazotrophicus was co-cultivated with $A$. thaliana seedlings, and its growth was analyzed during the first 24 hours of the association. Figure 1 shows that the presence of $A$. thaliana seedlings increased bacterial growth by approximately $45 \%$ after 24 hours of cocultivation. These data suggest that plant-produced metabolites are beneficial to bacterial growth. Microscopy analyses did not show morphological differences in G. diazotrophicus in response to cocultivation with $A$. thaliana (Fig. S2).

\subsection{A. thaliana seedlings constitutively exude metabolites that increase G. diazotrophicus growth}

To verify whether the exudation of beneficial metabolites by A. thaliana seedlings is constitutive or is induced by the presence of $G$. diazotrophicus, exudates from $G$.

diazotrophicus/A. thaliana cocultivation were compared to those produced by non-inoculated seedlings and by G. diazotrophicus cultured alone. Thus, MS media containing exudates from non-inoculated seedlings, from G. diazotrophicus cultures, and from G. diazotrophicus/A. thaliana cocultivation were obtained and added to new $G$. diazotrophicus cultures as shown in 
269 Figure S1. As a control, G. diazotrophicus was grown in the absence of exudates. Figure 2 shows

270 that exudates from non-inoculated A. thaliana (A. thaliana exudate) and G. diazotrophicus/A.

271 thaliana cocultivation (Co-cultive exudate) resulted in a similar increase in bacterial growth. As

272 expected, G. diazotrophicus cultured alone (G. diazotrophicus exudate) did not improve bacterial

273 growth. These results revealed that $A$. thaliana seedlings constitutively exude metabolites that

274 are beneficial for bacterial growth.

275

276

277

3.3 The proteomic profile of G. diazotrophicus alters in response to cocultivation with A. thaliana

278

The main G. diazotrophicus proteins regulated during cocultivation with A. thaliana 279 seedlings were investigated by comparative proteomic analysis. For this purpose, total protein 280 extracts obtained from co-cultivated bacteria were compared to those of bacteria cultivated in the absence of plants. A total of 450 bacterial proteins were identified (Table S1). Among these 282 proteins, 51 differentially accumulated proteins (DAPs) were observed, with 39 proteins increased, and 12 proteins decreased (Table 1 and Figure 3A).

\subsection{Protein networks regulated during cocultivation}

The functional association networks of the regulated proteins were analyzed with the down-accumulated proteins using a confidence level of 0.7 . Up-accumulated protein analysis revealed two major protein groups: "pentose-phosphate pathways" and "ribosomal proteins"

291 interaction networks between the proteins were identified (Fig. S3). 


\section{3.5 Main up-accumulated proteins}

294 Proteins that are potentially relevant to plant-bacteria interactions were up-accumulated

295 during the first 24 hours of cocultivation. Among these proteins, four showed the greatest up-

296 regulation: 5-methyltetrahydropteroyltriglutamate-homocysteine methyltransferase (MetE),

297 which is involved in the synthesis of methionine; aconitate hydratase (AcnA), which is

298 associated with the metabolism of tricarboxylic acids; energy-dependent translational throttle A

299 (EttA), which is involved in the regulation of ribosomal activity, and may also be necessary for

300 protection against antimicrobial compounds; ketol-acid reductoisomerase (IlvC), which is

301 involved in amino acid metabolism (Table 1).

302 Other up-accumulated proteins included Zwf (glucose-6-phosphate 1-dehydrogenase) and

303 Gnd (6-phosphogluconate dehydrogenase decarboxylating), which are related to the pentose-

304 phosphate pathway (Table 1). Another protein that was increased, ClpX (ATP-binding subunit of 305 the ClpXP protease), is involved in the degradation of unfolded proteins and is potentially related

306 to bacterial quorum sensing (Table 1). Additionally, a key protein for de novo fatty acid

307 biosynthesis, AccC (acetyl-CoA carboxylase biotin carboxylase subunit), and a protein involved

308 with nutrients uptake (TonB-dependent receptor) were also up-accumulated (Table 1).

\subsection{Down-accumulated proteins}

311 Only 12 proteins were down-accumulated in response to cocultivation. Among these

312 proteins, we highlight three transporters related to the import of sugars: OprB, a Sugar ABC

313 transporter substrate-binding protein, and the D-xylose $\mathrm{ABC}$ transporter substrate-binding 314 protein (Table 1). 
3163.7 Interruption of ettA and accC impairs $G$. diazotrophicus growth-response to cocultivation

317 with A. thaliana

318 Using reverse genetic analysis by mutagenesis approach, we checked whether specific

319 proteins, up-accumulated in our proteomic analysis, are essential for G. diazotrophicus response

320 to cocultivation with A. thaliana. Mutant strains defective for proteins potentially relevant for

321 bacterial growth/multiplication were selected. G. diazotrophicus mutant strains defectives for

322 EttA $(\Delta e t t A), \operatorname{AccC}(\Delta a c c C)$, and Zwf $(\Delta z w f)$ were co-cultivated with A. thaliana seedlings, and

323 their growth was analyzed in comparison to wild-type. Figure 4 shows that the lack of Zwf did

324 not affect $G$. diazotrophicus growth induction in response to cocultivation with $A$. thaliana. On

325 the other hand, the lack of EttA and AccC implies the loss of growth induction response,

326 suggesting a key role of these proteins in this process. Additionally, the growth of $\Delta a c c C$ in the

327 control treatment (MS) was significantly lower than the wild-type strain, suggesting that AccC is

328 also important to bacterial growth under normal culture conditions.

3303.8 In silico prediction suggests that ettA and acc C are organized in operons in $G$.

331 diazotrophicus genome

332

333 Phylogenetic analysis results for both $e t t A$ and $a c c C$ genes showed the formation of two

334 distinct groups (Fig. 5). The sequences of G. diazotrophicus are closer related to G. Xylinus and

335 A. brasiliense. Although H. seropedicae is a PGPB as G. diazotrophicus, its gene sequences are

336 closer to those from the phytopathogen P. syringae and the human pathogen E. coli (Fig. 5).

337 Moreover, operon prediction results suggest that both $e t t A$ and $a c c C$ are organized in operons in 
338 G. diazotrophicus genome. The operon that contains $a c c C$ is composed of three genes (aroQ,

$339 a c c B, a c c C)$ in almost all the bacterial species analyzed, except $E$. coli, which presents only two

340 genes in this operon ( $a c c B$ and $a c c C$ ) (Fig. 5a). In all bacterial species analyzed, $a c c C$ is in the

341 last position of the operon (Fig. 5A). So, the interruption in $\operatorname{accC}$ probably does not compromise

342 the transcription of the other components of such operon.

343 In almost all the bacterial species analyzed, ettA is not located in an operon, except in $G$.

344 diazotrophicus and G. xylinus (Fig. 5B). In these two species, ettA is located in an operon,

345 upstream of a gene that codifies a GCN5-related N-acetyltransferase (GNAT) family protein

346 (Fig. 5b). So, the interruption of ettA may compromise the production of a GNAT family protein

347 in G. diazotrophicus.

348

349

\section{Discussion}

350

The present work aimed to evaluate the response of $G$. diazotrophicus to cocultivation

351

352

353

354

355

356

357

358

359

360

with $A$. thaliana seedlings with an emphasis on the main bacterial proteins regulated by the interaction. Our results revealed the induction of bacterial growth during cocultivation, suggesting a beneficial effect of metabolites exuded by the plants. The data also revealed that the production of such plant-beneficial exudates is a constitutive process. Comparative proteomic analyses demonstrated the regulation of bacterial protein pathways that were mainly related to sugar metabolism (pentoses) and protein synthesis. Among the regulated proteins, MetE, AcnA, IlvC, EttA, Zwf, ClpX, and AccC deserve special attention.

Cocultivation with $A$. thaliana seedlings resulted in increased growth of $G$.

diazotrophicus (Figure 1). Studies that support this finding have been carried out with $G$.

diazotrophicus under cocultivation with sugarcane plants, where the induction of bacterial 
361 multiplication has been reported $[11,14]$. The substances exuded by plant roots include sugars,

362 amino acids, mucilage, flavonoids, organic acids, and volatile compounds capable of attracting

363 bacteria and favoring their multiplication [2]. Important functions have been attributed to exuded

364 sugars, which would serve as a source of energy for microorganisms [1,2,25]. However, a sugar-

365 rich culture medium ( $0.5 \%$ sucrose $)$ was used in the present work. Nevertheless, the presence of

366 exudates from A. thaliana seedlings positively modulated the growth of G. diazotrophicus,

367 suggesting contributions of other beneficial metabolites to this process.

368 The analysis of G. diazotrophicus growth in the presence of exudates from plants and

369 from plant-bacteria co-cultivation demonstrated that the production of beneficial metabolites by

370 plants is constitutive (Figure 2). Jacoby et al. (2018) showed that $A$. thaliana roots secrete a

371 large number of secondary metabolites that are used by bacteria. The amino acids valine,

372 tryptophan, threonine, and glutamine, in addition to pyrimidine and purine derivatives including

373 adenosine, cytidine, guanine, and uridine, are consumed by plant-associated bacteria [26].

374

Proteomic analyses revealed changes in the protein profile of G. diazotrophicus in

375 response to cocultivation, with 39 proteins classified as up-accumulated and 12 as down-

376 accumulated. Among the most up-accumulated proteins was 5-

377 methyltetrahydropteroyltriglutamate-homocysteine methyltransferase (MetE), which is involved

378 in the conversion of homocysteine to methionine [27]. Additionally, MetE is related to the

379 production of AI-2 quorum sensing (QS) molecule in different microorganisms [25]. However,

380 similar to the rest of the Alphaproteobacteria, G. diazotrophicus lacks a LuxS homolog required

381 for AI-2 synthesis [28], so the up-accumulation of MetE in our proteomic analysis should not be

382 related to QS activity. Another up-accumulated protein was Aconitate hydratase (AcnA), which

383 is associated with the metabolism of tricarboxylic acids and may protect bacterial cells from 
384 reactive oxygen species [29]. Ketol-acid reductoisomerase (IlvC), which was also up-

385 accumulated, plays an essential role in the pathway of amino acid biosynthesis [30]. These three

386 proteins were also detected among the most up-accumulated proteins of G. diazotrophicus during

387 its cocultivation with sugarcane plants [11]. Our results highlight the MetE, IlvC, and AcnA

388 proteins as potentially relevant for the association of G. diazotrophicus with both monocot and 389 dicot plants.

Approximately $23 \%$ of the up-accumulated proteins are ribosomal (RpsA, RpsB, RpsH,

391 RplE, RplF, RplN, and RplW), indicating a positive effect of cocultivation on bacterial protein

392 synthesis. In Escherichia coli, the genes coding for RpsH, RplE, RplF and RplN are in an operon

393 called $s p c$ that codes for 11 ribosomal proteins, essentials to protein synthesis machinery [31].

394 RpsA interacts with the mRNA leader sequence during the formation of the translation initiation

395 complex, acting directly in the regulation of such a process [32]. RpsA is also positively

396 regulated in the endophytic bacterium Herbaspirillum seropedicae when exposed to extracts

397 from sugarcane [33]. RplW is essential for bacterial multiplication and is associated with the

398 "Trigger Factor" in ribosomes [34,35]. Our data, therefore, suggest the activation of protein

399 synthesis as a critical response to cocultivation, supporting the increased bacterial growth 400 observed.

401 The proteomic analysis also revealed the up-accumulation of the ABC-F EttA protein 402 that modulates bacterial ribosomes activity in an energy-dependent manner [36]. In Escherichia 403 coli cells, the accumulation of EttA increases during the stationary phase, when energetic 404 resources decline [36]. In such a condition, EttA attaches to the ribosome and inhibits protein 405 synthesis [36]. In contrast, the increase in energy availability leads to the dissociation of EttA of 406 the ribosome, allowing it to enter the elongation cycle resuming protein synthesis [36]. 
407 Interestingly, even with our results showing that after 24 hours of cultivation G. diazotrophicus

408 still has available energy resources, characterized by its exponential growth phase, our proteomic

409 analysis showed the up-accumulation of EttA.

410 This result suggests that in G. diazotrophicus the regulation of EttA can be independent of

411 energy availability.

412 Additionally, the reverse genetics results showed that $\triangle e t t A$ mutant loses the growth

413 response to cocultivation with A. thaliana. ettA gene seems to belong to an operon in $G$.

414 diazotrophicus genome, located upstream of a gene that codifies a GCN5-related N-

415 acetyltransferase (GNAT) family protein. The phenotype observed for the $\Delta$ ettA mutant may be

416 the sum of effects caused by the absence of these two proteins (EttA and GNAT). GNATs are

417 widespread in eukaryotes and prokaryotes and are associated with many bacterial processes, such

418 as drug resistance, stress reaction, and regulation of transcription $[34,35]$. The result obtained to

$419 \Delta$ ettA allow us to speculate about the role of EttA in the perception of plant metabolites and the

420 subsequent activation of protein synthesis. However, further analyses are necessary to investigate

421 the participation of the protein GNAT in such a process.

422 Proteins of the pentose-phosphate pathway were also up-accumulated. This pathway is

423 essential for cell metabolism, including the maintenance of carbon homeostasis and the provision

424 of precursors for nucleotide and amino acid biosynthesis [39,40]. According to our data, four

425 members of this pathway were up-accumulated: Zwf (Glucose-6-phosphate 1-dehydrogenase),

426 Gnd (6-phosphogluconate dehydrogenase, decarboxylating), Gpml (2,3-bisphosphoglycerate-

427 independent phosphoglycerate mutase) and a Zwf homolog (A9H0G0). Among these proteins,

$428 \mathrm{Zwf}$ and Gnd function in the oxidative phase of the pentose-phosphate pathway, resulting in the

429 production of NADPH [41]. Despite the positive regulation of this pathway, our reverse genetics 
430 results demonstrate that the induction of $G$. diazotrophicus growth in response to $A$. thaliana

431 cocultivation was maintained even with the lack of $\mathrm{Zwf}(\mathrm{A} 9 \mathrm{H} 326)$. We hypothesize that the

432 activity of the Zwf homolog (A9H0G0), also up-accumulated in our proteomic analysis, may

433 compensate the absence of A9H326 in the pentose-phosphate pathway.

434 Additionally, among the proteins up-accumulated in our proteomic analysis potentially

435 involved with the bacterial response to plant exudates, $\mathrm{ClpX}$, and AccC deserve attention. ClpX

436 plays a role in the unfolding and degradation of other proteins. Additionally, it has been shown in

437 Burkholderia cenocepacia that a mutation in the ClpX coding sequence produces an increase in

438 the production of acyl homoserine lactone (AHLs), an important group of signaling molecules

439 for quorum sensing in gram-negative bacteria [42]. Proteins responsible for quorum sensing are

440 regulated in the presence of hosts and participate in the control of bacterial growth and the

441 regulation of virulence mechanisms [2,43,44]. Additional analyses are necessary to investigate

442 the role of $\mathrm{ClpX}$ in controlling unfolding proteins or in quorum sensing mechanisms in the

443 responses of $G$. diazotrophicus to metabolites exuded from A. thaliana seedlings.

AccC is a component of bacterial acetyl coenzyme-A carboxylase (ACCase) that

catalyzes the first step in fatty acid biosynthesis [45]. AccC participates in bacterial lipid

446 biosynthesis and consequently impacts cellular membrane formation, essential processes for cell

447 viability and bacterial growth [45]. Once G. diazotrophicus growth increased in response to $A$.

448 thaliana cocultivation, the increase in accumulation of AccC observed in our proteomic analyses

449 was expected. Our data using a defective mutant for AccC ( $\triangle a c c C)$ revealed a lower growth

450 performance in comparison to the wild-type strain. Bacterial multiplication requires the synthesis

451 of lipids to supply the formation of new cell membranes, which may explain our results.

452 Interestingly, another $a c c C$ homolog is present in the genome of G. diazotrophicus (GDI0201). 
453 However, the corresponding protein was not detected in our proteomic analyzes. The presence of

454 such a homolog gene in the genome of G. diazotrophicus did not compensate for the phenotype

455 of $\triangle a c c C$ in response to $A$. thaliana cocultivation observed in our results, suggesting a distinct

456 functional role.

457 Moreover, four proteins related to nutrients uptake were regulated in our proteomic

458 analysis. Among these, the protein TonB-dependent receptor (TBDRs) was highly up-

459 accumulated. TBDRs were described in early studies as an iron transporter. However, currently,

460 its activity is also associated with the active import of other nutrients, such as vitamins B1 and

461 B12 [46]. Molina et al. (2005), in a study with corn, showed that the efficiency of initial steps of

462 seed and root colonization by Pseudomonas putida is dependent of TBDR activity, once essential

463 mechanisms to this process, as biofilm formation, are highly iron-dependent [47]. Additionally,

464 the up-accumulation of TBDRs was previously reported in G. diazotrophicus in response to

465 sugarcane cocultivation [12]. Thus, our result reinforces the importance of TBDRs in plant-

466 bacteria associations.

467 The presence of sugars and other carbon structures in root exudates has been described as

468 the main factor in the induction of bacterial multiplication during the initial steps of plant-

469 bacteria interaction [48]. Moreover, in our assays, a high concentration of sugar was provided in

470 the culture medium. Our proteomic analysis showed that proteins related to sugars uptake (OprB,

471 Sugar $\mathrm{ABC}$ transporter substrate-binding, and D-xylose $\mathrm{ABC}$ transporter substrate-binding) were

472 down-accumulated in G. diazotrophicus cells co-cultivated with $A$. thaliana. The up-

473 accumulation of pentose-phosphate pathway proteins in our proteomic analysis reinforces that $G$.

474 diazotrophicus cells were under high availability of carbon sources in our assays. Previously

475 studies demonstrate that bacterial cells growing under high availability of carbon source exhibit 
476 high rates of carbon uptake and metabolism [49]. In this sense, further analyzes are necessary to

477 understand the role of the down-accumulation of proteins involved with sugar uptake at the

478 beginning of the association between $G$. diazotrophicus and A. thaliana seedlings.

479

480

\section{Conclusions}

481 Taken together, our data provide physiological and molecular aspects related to the

482 association between $G$. diazotrophicus and A. thaliana seedlings. As summarized in Figure 6, $A$.

483 thaliana seedlings constitutively exude beneficial metabolites that increase bacterial growth.

484 These data reinforce the potential involvement of the MetE, AcnA, IlvC, and TonB-dependent

485 receptor proteins as a conserved mechanism during the interaction of G. diazotrophicus with

486 both monocot and dicot plants. Additionally, our results revealed the essential role of the proteins

487 EttA and AccC in the bacterial growth activated in response to cocultivation with $A$. thaliana.

488 This is the first study to demonstrate the participation of EttA and AccC proteins in plant-

489 bacteria interactions. Our results open new perspectives for further investigations about the

490 initial steps of such associations in other bacteria and plant species.

491

492 References

4931 Dennis PG, Miller AJ \& Hirsch PR (2010) Are root exudates more important than other sources 494 of rhizodeposits in structuring rhizosphere bacterial communities? FEMS Microbiol. Ecol. $495 \quad$ 72, 313-327.

2 Sasse J, Martinoia E \& Northen T (2018) Feed Your Friends: Do Plant Exudates Shape the Root 497 Microbiome? Trends Plant Sci. 23, 25-41. 
4983 Grobelak A, Kokot P, Hutchison D, Grosser A \& Kacprzak M (2018) Plant growth-promoting

499 rhizobacteria as an alternative to mineral fertilizers in assisted bioremediation - Sustainable

$500 \quad$ land and waste management. J. Environ. Manage. 227, 1-9.

5014 Nkebiwe PM, Weinmann M \& Müller T (2016) Improving fertilizer-depot exploitation and 502 maize growth by inoculation with plant growth-promoting bacteria: From lab to field. Chem. 503 Biol. Technol. Agric. 3, 15.

5045 Lery LMS, Coelho A, Von Kruger WMA, Gonçalves MSM, Santos MF, Valente RH, Santos

505 EO, Rocha SLG, Perales J, Domont GB, Teixeira KRS \& Bisch PM (2008) Protein expression

506 profile of Gluconacetobacter diazotrophicus PAL5, a sugarcane endophytic plant growth507 promoting bacterium. Proteomics 8, 1631-1644.

5086 Zúñiga A, Donoso RA, Ruiz D, Ruz GA \& González B (2017) Quorum-Sensing Systems in the

509 Plant Growth-Promoting Bacterium Paraburkholderia phytofirmans PsJN Exhibit Cross-

510 Regulation and Are Involved in Biofilm Formation. Mol. Plant-Microbe Interact. 30, 557511565.

5127 Cavalcante VA \& Döbereiner J (1988) A new acid-tolerant nitrogen-fixing bacterium associated $513 \quad$ with sugarcane. Plant Soil 108, 23-31.

5148 Reis VM, Olivares FL, Döbereiner, J (1994) Improved methodology for isolation of Acetobacter 515 diazotrophicus and confirmation of its endophytic habitat. World J. Microbiol. Biotechnol. $516 \quad \mathbf{1 0}, 401-5$.

5179 Souza ALSR, De Souza SA, De Oliveira MV V., Ferraz TM, Figueiredo FAMMA, Da Silva 518 ND, Rangel PL, Panisset CRS, Olivares FL, Campostrini E \& De Souza Filho GA (2016) 
519 Endophytic colonization of Arabidopsis thaliana by Gluconacetobacter diazotrophicus and its

520 effect on plant growth promotion, plant physiology, and activation of plant defense. Plant $521 \quad$ Soil 399, 257-270.

52210 Bertalan M, Albano R, de Pádua V, Rouws L, Rojas C, Hemerly A, Teixeira K, Schwab S, 523 Araujo J, Oliveira A, França L, Magalhães V, Alquéres S, Cardoso A, Almeida W, Loureiro 524 M, Nogueira E, Cidade D, Oliveira D, Simão T, Macedo J, Valadão A, Dreschsel M, Freitas

525 F, Vidal M, Guedes H, Rodrigues E, Meneses C, Brioso P, Pozzer L, Figueiredo D, Montano 526 H, Junior J, de Souza Filho G, Martin Quintana Flores V, Ferreira B, Branco A, Gonzalez P, 527 Guillobel H, Lemos M, Seibel L, Macedo J, Alves-Ferreira M, Sachetto-Martins G, Coelho 528 A, Santos E, Amaral G, Neves A, Pacheco A, Carvalho D, Lery L, Bisch P, Rössle SC, 529 Ürményi T, Rael Pereira A, Silva R, Rondinelli E, von Krüger W, Martins O, Baldani J \& $530 \quad$ Ferreira PC (2009) Complete genome sequence of the sugarcane nitrogen-fixing endophyte 531 Gluconacetobacter diazotrophicus Pal5. BMC Genomics 10, 450.

53211 Lery LMS, Hemerly AS, Nogueira EM, Von Krüger WMA \& Bisch PM (2011) Quantitative 533 Proteomic Analysis of the Interaction Between the Endophytic Plant-Growth-Promoting 534 Bacterium Gluconacetobacter diazotrophicus and Sugarcane. Mol. Plant-Microbe Interact. 535 MPMI 24, 562-576.

12 Meneses C, Gonçalves T, Alquéres S, Rouws L, Serrato R, Vidal M \& Baldani JI (2017) 537 Gluconacetobacter diazotrophicus exopolysaccharide protects bacterial cells against 538 oxidative stress in vitro and during rice plant colonization. Plant Soil 416, 133-147.

13 Rangel de Souza ALS et al. (2016) Endophyt colonization of Arabidopsis thaliana by 540 Gluconacetobacter diazotrophicus and its effect on plant growth promotion, plant physiology, 

and activation of plant defense. Plant Soil 399, 257-270.

54214 dos Santos MF, Muniz de P??dua VL, de Matos Nogueira E, Hemerly AS \& Domont GB (2010)

543 Proteome of Gluconacetobacter diazotrophicus co-cultivated with sugarcane plantlets. J. $544 \quad$ Proteomics 73, 917-931.

54515 S G Meneses CH, M Rouws LF, Simões-Araújo JL, Vidal MS \& Baldani JI (2011) 546 Exopolysaccharide Production Is Required for Biofilm Formation and Plant Colonization by 547 the Nitrogen-Fixing Endophyte Gluconacetobacter diazotrophicus. Mol. Plant-Microbe $548 \quad$ Interact. MPMI 24, 1448-1458.

16 Murashige, T.; Skoog F (1962) A Revised Medium for Rapid Growth and Bio Assays with 550 Tobacco Tissue Cultures. Physiol. Plant. 15, 473-497.

17 Intorne AC, De Oliveira MV V, Lima ML, da Silva JF, Olivares FL, de Souza Filho GA, Oliveira MV V, Lima ML, da Silva JF, Olivares FL \& de Souza Filho GA (2009) Identification and characterization of Gluconacetobacter diazotrophicus mutants defective in

18 Passamani LZ, Barbosa RR, Reis RS, Heringer AS, Rangel PL, Santa-Catarina C, Grativol C, Veiga CFM, Souza-Filho GA \& Silveira V (2017) Salt stress induces changes in the proteomic profile of micropropagated sugarcane shoots. PLoS One.

19 Nanjo Y, Skultety L, Uváčková L, Klubicová K, Hajduch M \& Komatsu S (2012) Mass Spectrometry-Based Analysis of Proteomic Changes in the Root Tips of Flooded Soybean Seedlings. J. Proteome Res. 11, 372-385. 
56120 Passamani LZ, Bertolazi AA, Ramos AC, Santa-Catarina C, Thelen JJ \& Silveira V (2018)

562 Embryogenic Competence Acquisition in Sugar Cane Callus Is Associated with Differential

563 H+-Pump Abundance and Activity. J. Proteome Res. 17, 2767-2779.

56421 Distler U, Kuharev J, Navarro P \& Tenzer S (2016) Label-free quantification in ion mobility565 enhanced data-independent acquisition proteomics. Nat. Protoc. 11, 795-812.

56622 Distler U, Kuharev J, Navarro P, Levin Y, Schild H \& Tenzer S (2014) Drift time-specific

567 collision energies enable deep-coverage data-independent acquisition proteomics. Nat.

$568 \quad$ Methods 11, 167-170.

569

570

571

572

573

574

575

576

577

578

579

23 Leandro MR, Rangel PL, dos Santos TC, Andrade LF, de Souza Vespoli L, Rangel ALS, de Souza SA, Barbosa RR, Passamani LZ, Silveira V \& de Souza Filho GA (2019) Colonization of Arabidopsis thaliana by Herbaspirillum seropedicae promotes its growth and changes its proteomic profile. Plant Soil.

24 Kumar S, Stecher G, Li M, Knyaz C \& Tamura K (2018) MEGA X: Molecular evolutionary genetics analysis across computing platforms. Mol. Biol. Evol.

25 Badri D V. \& Vivanco JM (2009) Regulation and function of root exudates. Plant. Cell Environ. 32, 666-681.

26 Jacoby RP, Martyn A \& Kopriva S (2018) Exometabolomic Profiling of Bacterial Strains as Cultivated Using Arabidopsis Root Extract as the Sole Carbon Source. Mol. Plant-Microbe Interact. 31, 803-813.

27 Winzer K (2002) Bacterial cell-to-cell communication: sorry, can't talk now — gone to lunch! 
Curr. Opin. Microbiol. 5, 216-222.

58228 Rezzonico F \& Duffy B (2008) Lack of genomic evidence of AI-2 receptors suggests a non583 quorum sensing role for luxS in most bacteria. BMC Microbiol.

58429 Doi Y \& Takaya N (2015) A novel A3 group aconitase tolerates oxidation and nitric oxide. $J$. 585 Biol. Chem. 290, 1412-21.

586

587

588

589 590

591

592

593

594

595

596

597

598

599

600

30 Li KH, Yu YH, Dong HJ, Zhang W Bin, Ma JC \& Wang HH (2017) Biological functions of ilvC in branched-chain fatty acid synthesis and diffusible signal factor family production in Xanthomonas campestris. Front. Microbiol. 8, 2486.

31 Aseev L V. \& Boni I V. (2011) Extraribosomal functions of bacterial ribosomal proteins. Mol. Biol.

32 Komarova A V, Tchufistova LS, Supina E V \& Boni I V (2002) Protein S1 counteracts the inhibitory effect of the extended Shine-Dalgarno sequence on translation. $R N A \mathbf{8}, 1137-47$.

33 Cordeiro FA, Tadra-Sfeir MZ, Huergo LF, de Oliveira Pedrosa F, Monteiro RA \& de Souza EM (2013) Proteomic Analysis of Herbaspirillum seropedicae Cultivated in the Presence of Sugar Cane Extract. J. Proteome Res. 12, 1142-1150.

34 Kramer G, Rauch T, Rist W, Vorderwülbecke S, Patzelt H, Schulze-Specking A, Ban N, Deuerling E \& Bukau B (2002) L23 protein functions as a chaperone docking site on the ribosome. Nature 419, 171-174.

35 Tischendorf GW, Zeichhardt H \& Stöffler G (1974) Determination of the location of proteins L14, L17, L18, L19, L22 and L23 on the surface of the 50S ribosomal subunit of Escherichia 

coli by immune electron microscopy. MGG Mol. Gen. Genet. 134, 187-208.

60236 Boël G, Smith PC, Ning W, Englander MT, Chen B, Hashem Y, Testa AJ, Fischer JJ, Wieden 603 HJ, Frank J, Gonzalez RL \& Hunt JF (2014) The ABC-F protein EttA gates ribosome entry 604 into the translation elongation cycle. Nat. Struct. Mol. Biol. 21, 143-151.

37 Xie L, Zeng J, Luo H, Pan W \& Xie J (2014) The roles of bacterial GCN5-Related N606 acetyltransferases. Crit. Rev. Eukaryot. Gene Expr.

38 Favrot L, Blanchard JS \& Vergnolle O (2016) Bacterial GCN5-Related N-Acetyltransferases: From Resistance to Regulation. Biochemistry.

39 Pickl A \& Schönheit P (2015) The oxidative pentose phosphate pathway in the haloarchaeon 610 Haloferax volcanii involves a novel type of glucose-6-phosphate dehydrogenase - The 611 archaeal Zwischenferment. FEBS Lett. 589, 1105-1111.

40 Stincone A, Prigione A, Cramer T, Wamelink MMC, Campbell K, Cheung E, Olin-Sandoval 613 V, Grüning N-M, Krüger A, Tauqeer Alam M, Keller MA, Breitenbach M, Brindle KM, 614 Rabinowitz JD \& Ralser M (2015) The return of metabolism: biochemistry and physiology 615 of the pentose phosphate pathway. Biol. Rev. 90, 927-963.

41 Lim S-J, Jung Y-M, Shin H-D \& Lee Y-H (2002) Amplification of the NADPH-related genes zwf and gnd for the oddball biosynthesis of PHB in an E. coli transformant harboring a cloned phbCAB operon. J. Biosci. Bioeng. 93, 543-549.

42 Veselova MA, Romanova YM, Lipasova VA, Koksharova OA, Zaitseva Y V., Chernukha MU, 620 Gintsburg AL \& Khmel IA (2016) The effect of mutation in the clpX gene on the synthesis 
621 of N-acyl-homoserine lactones and other properties of Burkholderia cenocepacia 370.

622 Microbiol. Res. 186-187, 90-98.

62343 Pérez-Montaño F, Jiménez-Guerrero I, Contreras Sánchez-Matamoros R, López-Baena FJ, 624 Ollero FJ, Rodríguez-Carvajal MA, Bellogín RA \& Espuny MR (2013) Rice and bean AHL625 mimic quorum-sensing signals specifically interfere with the capacity to form biofilms by 626 plant-associated bacteria. Res. Microbiol. 164, 749-760.

627

628

629

630

631

632

633

634

635

636

637

638

639

640

44 Steindler L, Bertani I, De Sordi L, Schwager S, Eberl L \& Venturi V (2009) LasI/R and RhlI/R quorum sensing in a strain of Pseudomonas aeruginosa beneficial to plants. Appl. Environ. Microbiol. 75, 5131-40.

45 Cheng CC, Shipps GW, Yang Z, Sun B, Kawahata N, Soucy KA, Soriano A, Orth P, Xiao L, Mann P \& Black T (2009) Discovery and optimization of antibacterial AccC inhibitors. Bioorganic Med. Chem. Lett. 19, 6507-6514.

46 Schauer K, Rodionov DA \& de Reuse H (2008) New substrates for TonB-dependent transport: do we only see the "tip of the iceberg"? Trends Biochem. Sci. 33, 330-338.

47 Molina MA, Godoy P, Ramos-González MI, Muñoz N, Ramos JL \& Espinosa-Urgel M (2005) Role of iron and the TonB system in colonization of corn seeds and roots by Pseudomonas putida KT2440. Environ. Microbiol.

48 Babalola OO (2010) Beneficial bacteria of agricultural importance. Biotechnol. Lett.

49 Russell JB \& Cook GM (1995) Energetics of bacterial growth: Balance of anabolic and catabolic reactions. Microbiol. Rev. 
641

Peer) reviewing PDF | (2020:03:46492:1:1:NEW 10 Jun 2020) 
Figure 1

G. diazotrophicus growth increases in response to cocultivation with $A$. thaliana seedlings.

G. diazotrophicus (Gd) was co-cultivated with $A$. thaliana seedlings (At), and its growth was analyzed every two hours during the first 24 hours of cocultivation.

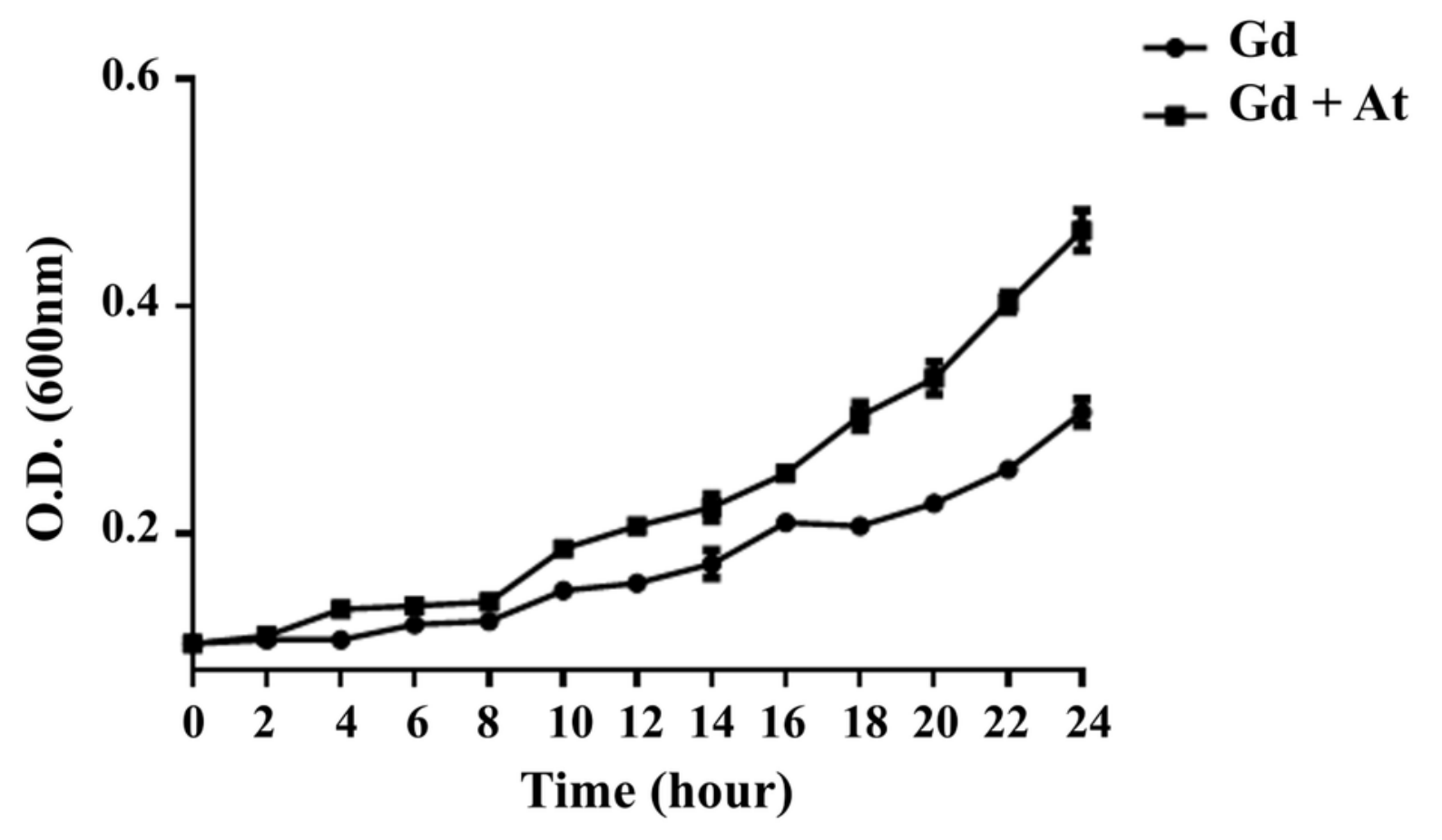




\section{Figure 2}

A. thaliana exudates that increase $G$. diazotrophicus growth are produced constitutively.

Exudates from non-inoculated $A$. thaliana seedlings, from $G$. diazotrophicus cultures, and from $G$. diazotrophicus/A. thaliana cocultivation were added to new $G$. diazotrophicus cultures and its growth was analyzed after 24 hours of treatment. Control treatment represents bacterial growth in the absence of exudates. Different letters indicate significant differences from the control by the Tukey test at $5 \%$ probability $(n=9)$.

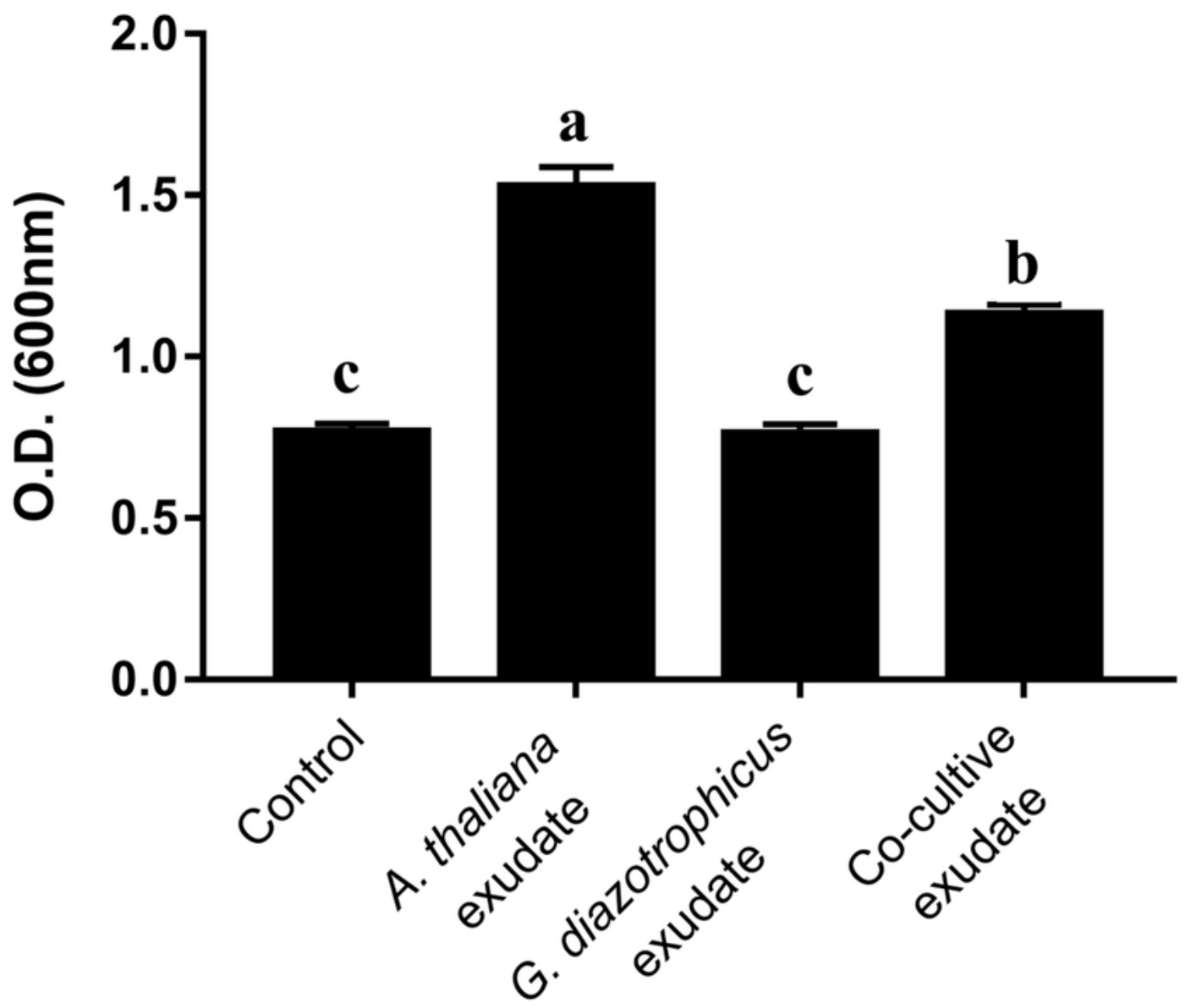




\section{Figure 3}

Analyses of identified proteins of $G$. diazotrophicus co-cultivated with $A$. thaliana seedlings.

Volcano plot of all identified proteins and graphical representation of the percentages of DAPs up-accumulated (blue) and down-accumulated (red) of G. diazotrophicus co-cultivated with $A$. thaliana (A). The spots represent differential abundance (log2 fold change) of identified proteins in function of statistical significance $(-\log 10 \mathrm{p}$ value). (B) Protein networks of DAPs up-accumulated during cocultivation. Colored proteins represent clustered proteins from "protein synthesis pathway" (green) and "pentose-phosphate pathway" (yellow).
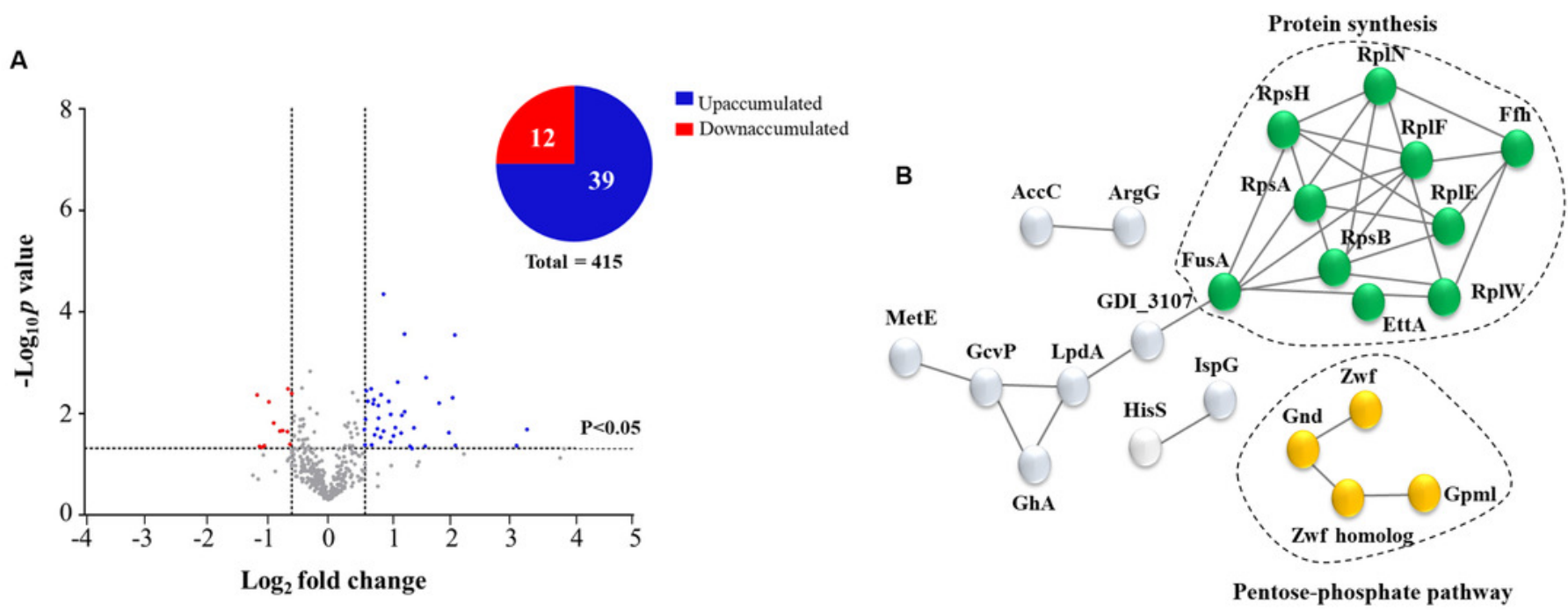


\section{Figure 4}

Reverse genetics revealed $G$. diazotrophicus genes involved with response to $A$. thaliana cocultivation

Insertional mutants of $G$. diazotrophicus defectives in production of three proteins upaccumulated in our proteomic analysis were selected to perform cocultivation assay with $A$. thaliana seedlings. The growth of each strain was analyzed after 24 hours of cocultivation. Different letters indicate significant differences from the control by the Tukey test at $5 \%$ probability $(n=9)$.

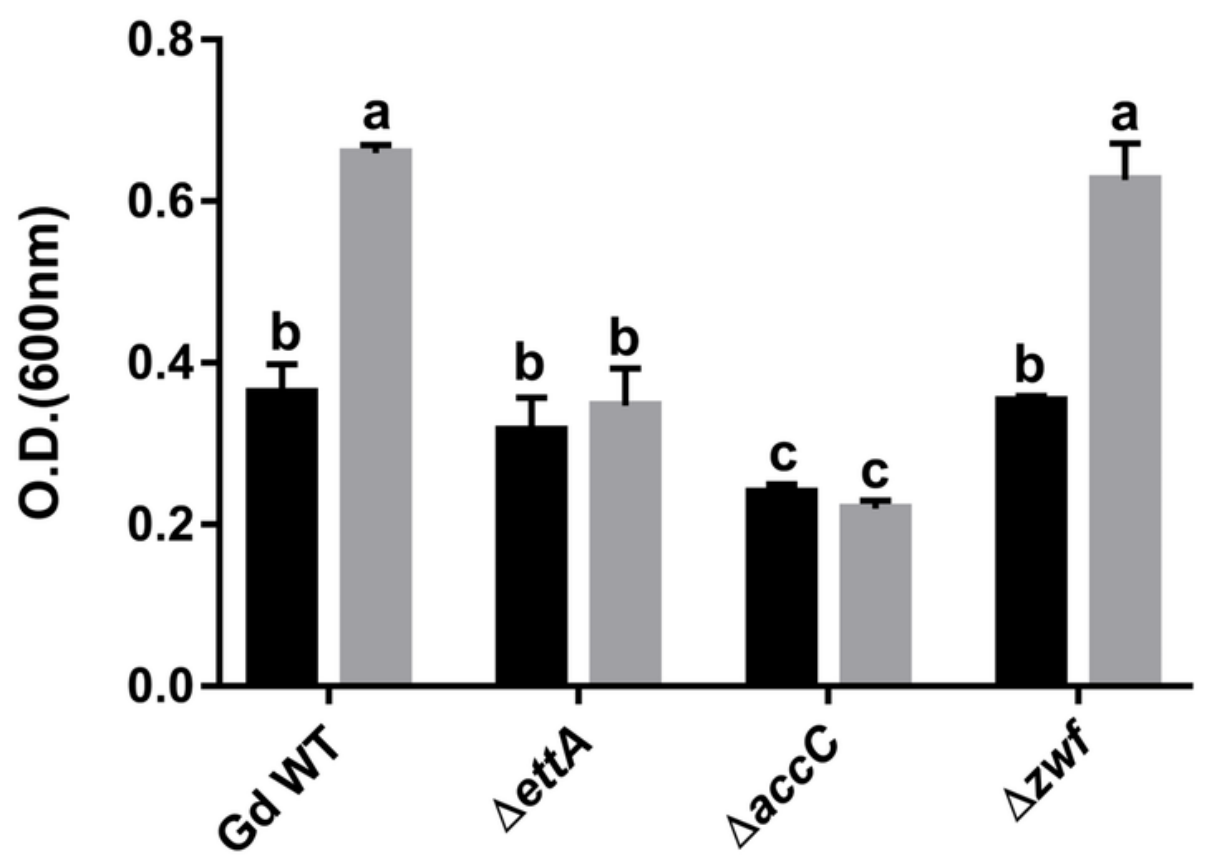




\section{Figure 5}

Phylogenetic analysis and in silico operon prediction of accC and ettA.

Phylogenetic relationship of the nucleotide sequences and gene cluster flanking $\operatorname{accC}(\mathrm{A})$ and ettA (B) in G. diazotrophicus PAl 5 (RefSeq: NC_010125.1) and related bacterial species following the RefSeq NCBI database: G. xylinus NBRC 3288 (RefSeq: NC_016037), A. brasilense Sp245 (RefSeq: NZ_CP022253.1), Herbaspirillum seropedicae SmR1 (RefSeq: NC_014323), P. syringae pv. tomato str. DC3000 (RefSeq: NC_004578.1), and E. coli ATCC 8739 (RefSeq: NZ_CP022959.1). The numbers at the nodes indicate bootstrap support. Arrows indicate the orientations of genes translation. Codes above genes are the locus tag of the gene sequences that do not have a described abbreviation. Asterisks indicate uncharacterized genes. Triangles: transposon insertion sites; SSR: Site-specific recombinases, phase integrase family genes; $A B C-t$ : $A B C$-transporter family genes; GNAT: GCN5-related N-acetyltransferases family genes; BASS: Bile Acid: Na+ Symporter family gene. 
A

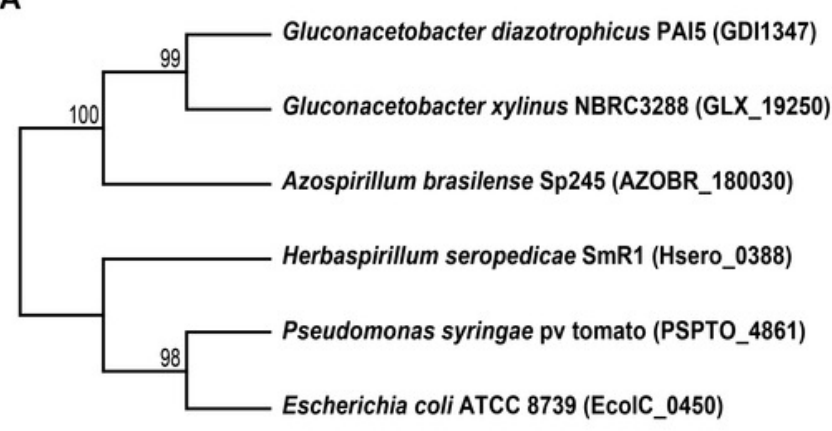

B

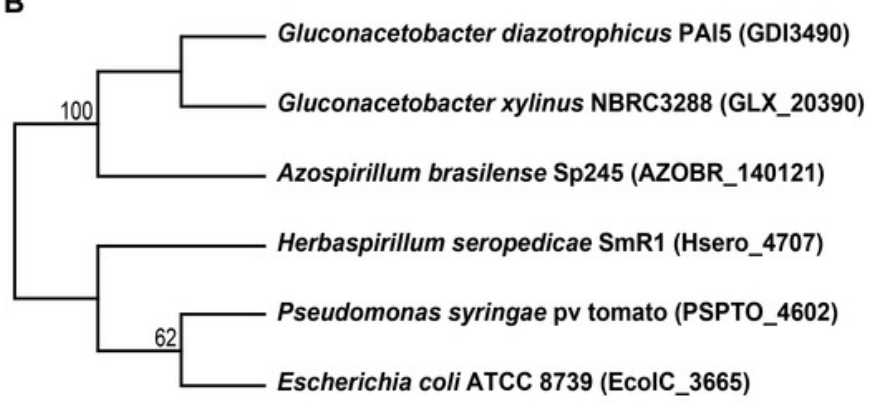

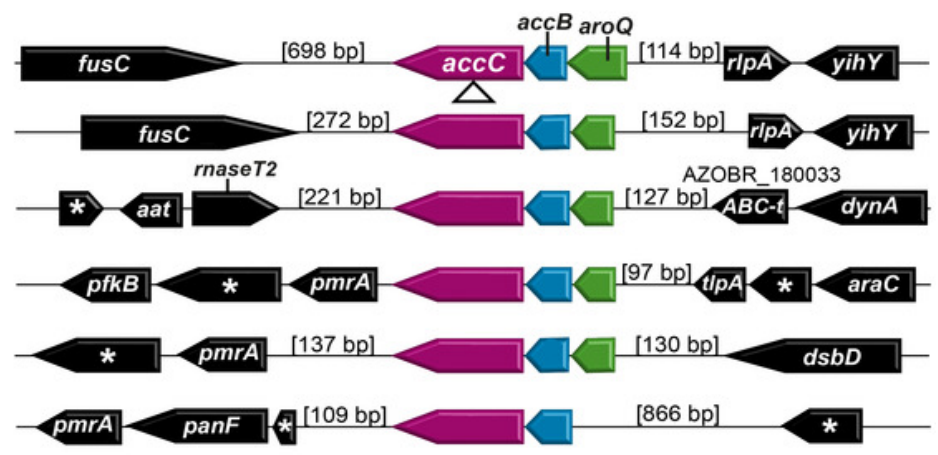

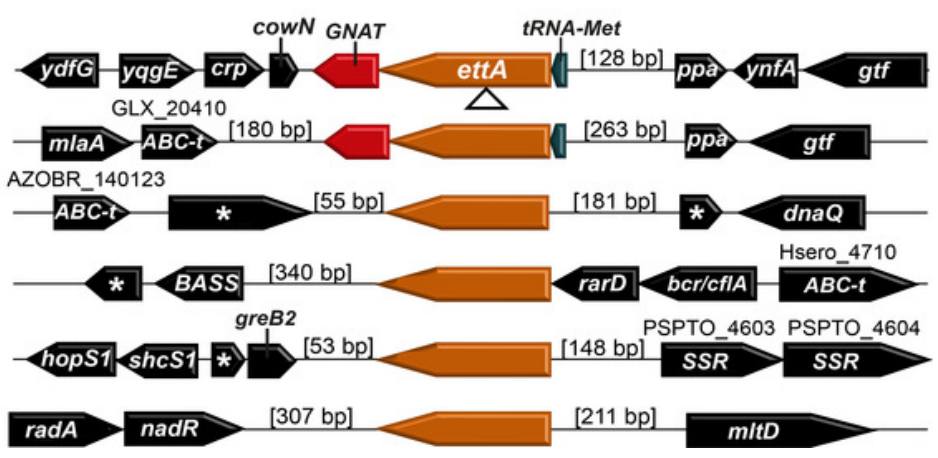


Figure 6

Schematic illustration of the main responses of $G$. diazotrophicus to beneficial metabolites exuded by $A$. thaliana.

Colored circles represent metabolites exuded from the plant. Brown boxes indicate $G$. diazotrophicus proteins that have also been up-accumulated in proteomic studies performed with other plant species.

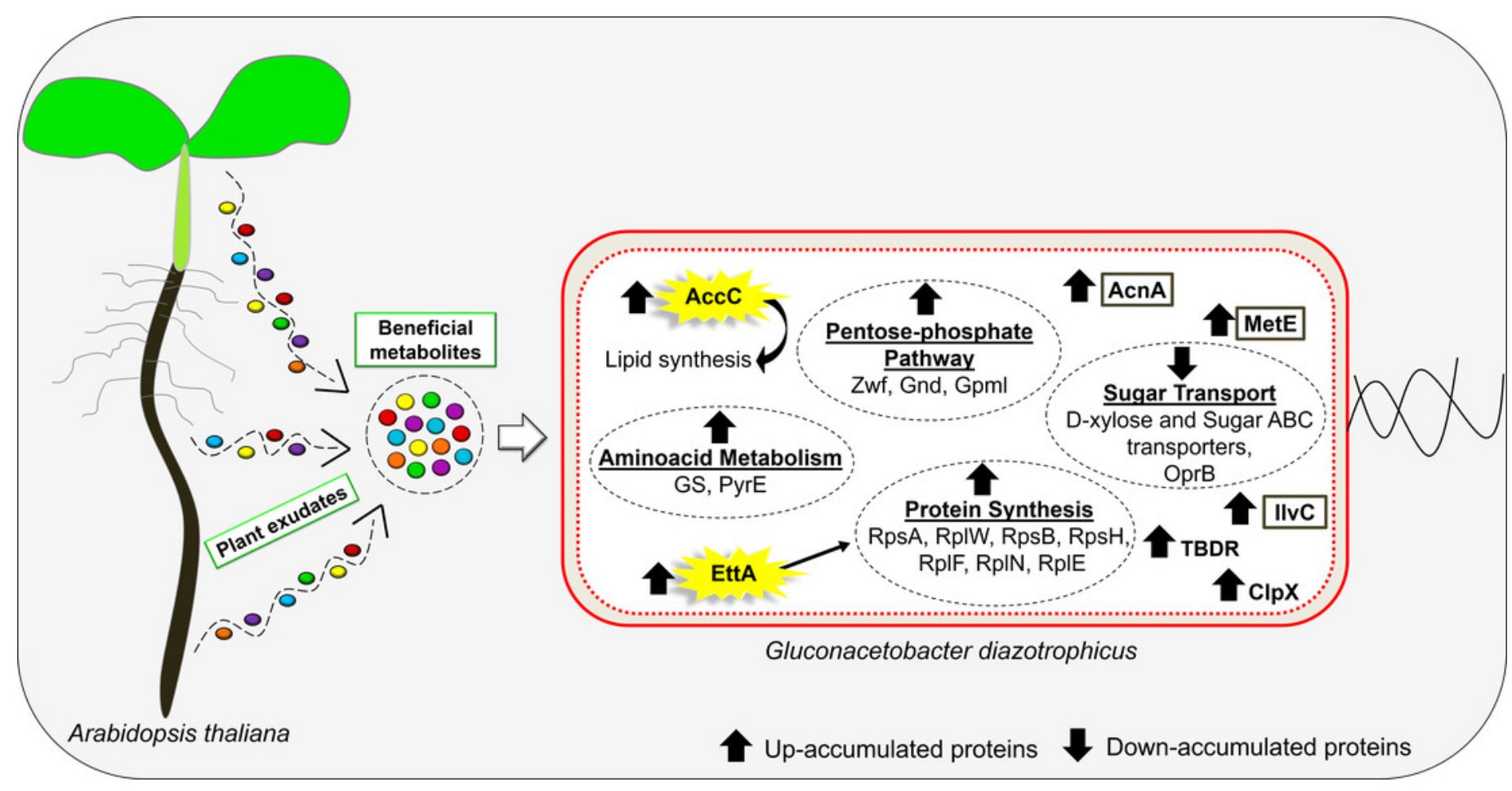


Table $\mathbf{1}$ (on next page)

Table 1. G. diazotrophicus proteins regulated in response to cocutiltivation with $A$. thaliana 
Table 1. G. diazotrophicus proteins regulated in response to cocutiltivation with A. thaliana

\begin{tabular}{|c|c|c|c|c|c|}
\hline Accession & Description & Gene & $\begin{array}{c}\text { Reported } \\
\text { Peptides }\end{array}$ & $\begin{array}{c}\text { Max } \\
\text { Score }\end{array}$ & $\begin{array}{c}\text { Fold } \\
\text { Change }\end{array}$ \\
\hline \multicolumn{6}{|c|}{ Up-accumulated } \\
\hline A9HSA5 & Putative thioredoxin protein & GDI3107 & 4,00 & 3216,44 & 1,50 \\
\hline RL23 & 50S ribosomal protein L23 & rplW & 6,00 & 8093,88 & 1,52 \\
\hline A9HIP1 & S-(hydroxymethyl)glutathione dehydrogenase & frmA & 4,00 & 1057,50 & 1,52 \\
\hline A9H0G0 & Glucose-6-phosphate 1-dehydrogenase & zwf & 27,00 & 5629,12 & 1,54 \\
\hline RS2 & $30 \mathrm{~S}$ ribosomal protein $\mathrm{S} 2$ & rpsB & 16,00 & 11963,12 & 1,56 \\
\hline A9HDU1 & Oxidoreductase domain protein & GDI1200 & 14,00 & 6904,23 & 1,63 \\
\hline A9HAZ8 & Protein TolR & tolR & 3,00 & 1454,51 & 1,64 \\
\hline A9HJY0 & Putative transcriptional Regulator, MarR family & GDI_2027 & 4,00 & 6080,51 & 1,67 \\
\hline A9H0W3 & Adenylyl-sulfate kinase & cysC & 21,00 & 4170,78 & 1,68 \\
\hline A9HM86 & Glycine--tRNA ligase beta subunit & glyrs & 11,00 & 1189,10 & 1,69 \\
\hline A9HS68 & Signal recognition particle protein & ffh & 12,00 & 2042,15 & 1,75 \\
\hline A9HGY2 & Putative Squalene--hopene cyclase & GDI1620 & 2,00 & 350,53 & 1,77 \\
\hline A9HJS1 & Uncharacterized protein & GDI1999 & 4,00 & 769,19 & 1,77 \\
\hline RS8 & $30 \mathrm{~S}$ ribosomal protein $\mathrm{S} 8$ & rpsH & 6,00 & 4884,06 & 1,81 \\
\hline SYH & Histidine--tRNA ligase & hisS & 6,00 & 728,77 & 1,82 \\
\hline A9H324 & 6-phosphogluconate dehydrogenase, decarboxylating & gnd & 16,00 & 20323,17 & 1,87 \\
\hline ASSY & Argininosuccinate synthase & $\operatorname{argG}$ & 10,00 & 4334,52 & 1,87 \\
\hline A9HRE6 & Putative metallopeptidase & GDI2948 & 19,00 & 3042,59 & 1,98 \\
\hline RL6 & 50S ribosomal protein L6 & rplF & 9,00 & 8968,96 & 2,03 \\
\hline A9H397 & 2,3-bisphosphoglycerate-independent phosphoglycerate mutase & gpmI & 11,00 & 4303,62 & 2,03 \\
\hline A9HJB6 & Dihydrolipoyl dehydrogenase & $\operatorname{lpdA}$ & 8,00 & 1282,86 & 2,09 \\
\hline A9HM48 & Glycine dehydrogenase (decarboxylating) & gcvP & 20,00 & 1964,67 & 2,14 \\
\hline A9H7Z5 & Glutamine synthetase & $\operatorname{gln} \mathrm{A}$ & 23,00 & 15678,34 & 2,20 \\
\hline A9HII0 & Orotate phosphoribosyltransferase & pyrE & 5,00 & 3799,75 & 2,29 \\
\hline
\end{tabular}




\begin{tabular}{|c|c|c|c|c|c|}
\hline A9H108 & Glutamate--cysteine ligase & GDI3250 & 7,00 & 1745,48 & 2,30 \\
\hline A9H459 & 30S ribosomal protein S1 & rpsA & 30,00 & 11955,40 & 2,38 \\
\hline RL14 & 50S ribosomal protein L14 & rplN & 4,00 & 2991,02 & 2,38 \\
\hline А9H326 & Glucose-6-phosphate 1-dehydrogenase & zwf & 5,00 & 837,57 & 2,53 \\
\hline А9H3M8 & 50S ribosomal protein L5 & rplE & 4,00 & 1646,31 & 2,58 \\
\hline CLPX & ATP-dependent Clp protease ATP-binding subunit ClpX & $\operatorname{clpX}$ & 11,00 & 3303,25 & 2,64 \\
\hline ISPG & 4-hydroxy-3-methylbut-2-en-1-yl diphosphate synthase (flavodoxin) & ispG & 6,00 & 1571,93 & 3,00 \\
\hline A9GZU8 & Conserved protein & GDI0061 & 7,00 & 1962,62 & 3,04 \\
\hline A9HEX0 & acetyl-CoA carboxylase biotin carboxylase subunit & accC & 13,00 & 4423,06 & 3,52 \\
\hline A9HS02 & Elongation factor $\mathrm{G}$ & fusA & 31,00 & 10183,21 & 3,93 \\
\hline A9H932 & TonB-dependent receptor & GDI0667 & 14,00 & 2074,37 & 4,10 \\
\hline ILVC & Ketol-acid reductoisomerase $(\mathrm{NADP}(+))$ & ilvC & 5,00 & 2463,85 & 4,21 \\
\hline A9H4G2 & Energy-dependent translational throttle A protein EttA & ettA & 5,00 & 506,79 & 4,23 \\
\hline A9HEZ2 & Aconitate hydratase & acnA & 44,00 & 10076,64 & 8,49 \\
\hline A9HNX4 & 5-methyltetrahydropteroyltriglutamate--homocysteine methyltransferase & metE & 38,00 & 11719,34 & 9,56 \\
\hline \multicolumn{6}{|c|}{ Down-accumulated } \\
\hline A9HB99 & Uncharacterized protein & GDI0843 & 4,00 & 10074,54 & 0,44 \\
\hline A9HPF6 & Porin & oprB & 9,00 & 2838,53 & 0,46 \\
\hline A9H577 & Sugar $A B C$ transporter substrate-binding protein & GDI0354 & 8,00 & 4390,16 & 0,47 \\
\hline A9H073 & Alcohol dehydrogenase GroES domain protein & GDI_3142 & 4,00 & 1094,65 & 0,48 \\
\hline A9HRF1 & Succinate--CoA ligase [ADP-forming] subunit alpha & sucD & 5,00 & 2866,13 & 0,51 \\
\hline А9HРH9 & $10 \mathrm{kDa}$ chaperonin & groS & 5,00 & 4835,59 & 0,54 \\
\hline A9HNP0 & D-xylose $\mathrm{ABC}$ transporter, periplasmic substrate-binding protein & xylF & 18,00 & 13607,54 & 0,58 \\
\hline A9HK34 & Cold-shock DNA-binding domain protein & GDI2048 & 5,00 & 34042,72 & 0,59 \\
\hline A9HEI5 & Uncharacterized protein & GDI1295 & 3,00 & 3273,24 & 0,63 \\
\hline А9H9C0 & Inosine-guanosine kinase & GDI0702 & 4,00 & 1497,69 & 0,63 \\
\hline A9HL73 & Alanine--tRNA ligase & alaS & 13,00 & 1109,99 & 0,64 \\
\hline A9HPE1 & Extracellular solute-binding protein family 1 & GDI2634 & 13,00 & 9768,71 & 0,66 \\
\hline
\end{tabular}

